\title{
The Effect of Morphology on Gas Permeability and Permselectivity in Polyimide Based on 3,3',4,4'-Biphenyltetracarboxylic Dianhydride and 4,4'-Oxydianiline
}

\author{
Kazuhiro TANAKA, ${ }^{*}$ Hidetoshi KITA, ${ }^{*}$ Ken-ichi OKamoto, ${ }^{*}$ \\ Asumaru NAKAMURA, ${ }^{* *}$ and Yoshihiro KUSUKI ${ }^{* * *}$ \\ * Department of Chemical Engineering, Faculty of Engineering, \\ Yamaguchi University, Ube, Yamaguchi 755, Japan \\ ** Corporate Research and Development, Ube Industries Ltd., \\ Akasaka, Minato-ku, Tokyo 107, Japan \\ *** Chiba Laboratory, Corporate Research and Development, \\ Ube Industries Ltd., Ichihara, Chiba 290, Japan
}

(Received June 6, 1988)

\begin{abstract}
The permeability and diffusion coefficients for $\mathrm{H}_{2}, \mathrm{CO}, \mathrm{CO}_{2}$, and $\mathrm{CH}_{4}$ through

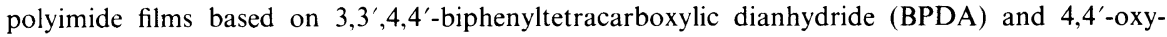
dianiline (ODA) decreased, but their activation energies increased with decrease in specific volume, which reflected the average degree of molecular aggregation of the polymer. The changes were greater for gases with larger molecular diameters. The solubility coefficients also decreased with decrease in specific volume but the sorption enthalpies hardly changed. The decreases were hardly dependent on the molecular size of the gases and were similar to the decreases in the diffusion coefficient for $\mathrm{H}_{2}$. With decrease in specific volume, the permselectivity was enhanced significantly for the $\mathrm{H}_{2} / \mathrm{CO}$ and $\mathrm{H}_{2} / \mathrm{CH}_{4}$ systems at the sacrifice of the permeability, but not for the $\mathrm{CO}_{2} / \mathrm{CH}_{4}$ system. There was no appreciable difference in the permeation properties attributed to the difference in the film-casting method.

KEY WORDS Gas Separation/Permeation / Sorption/ Diffusion Coefficient / Polyimide / Morphology / Annealing /
\end{abstract}

Polyimides with excellent thermal and mechanical durability, including polyimides based on pyromellitic dianhydride (PMDA), have attracted much attention as materials applicable to gas separation at high temperatures. ${ }^{1-9}$ Contrary to the fact that PMDAbased polyimides are not soluble in any solvent, the polyimides prepared from $3,3^{\prime}, 4,4^{\prime}$ biphenyltetracarboxylic dianhydride (BPDA) and aromatic diamines such as 4,4'-oxydianiline (ODA) and soluble in $p$-chlorophenol and have been successfully fabricated into asymmetric hollow fibers. ${ }^{5}$

In the previous paper, ${ }^{9}$ it was found that ascast films of BPDA-ODA polyimide are amorphous and the films annealed above the glass transition temperature $\left(T_{\mathrm{g}}\right)$ have some degree of ordering due to the molecular aggregation of polymer chain segments. The $\mathrm{CO}_{2}$ sorption and transport properties of these BPDA-ODA polyimide films were influenced by morphology. The influence of morphology on the parameters in the dual-mode sorption and transport model ${ }^{10}$ was discussed in comparison with that reported for poly(ethylene terephthalate) (PET), a typical semicrystalline glassy polymer.

In this paper, the permeation experiments for $\mathrm{H}_{2}, \mathrm{CO}, \mathrm{CO}_{2}$, and $\mathrm{CH}_{4}$ through BPDAODA polyimide films prepared by different film-casting methods and annealed under different conditions were carried out, and the 
effects of the casting methods and the morphology of the films on the permeability and permselectivity are discussed.

\section{EXPERIMENTAL}

Sample films of BPDA-ODA polyimide used in this study are listed in Table I. They were prepared by different film-casting methods and annealed under different conditions. BO-1 to BO-5 were prepared by casting a $p$ chlorophenol solution of the polyimide followed by annealing under different conditions, as described in the previous paper. ${ }^{9} \mathrm{BO}-\mathrm{A} 1$ and $\mathrm{BO}-\mathrm{A} 2$ were prepared by casting a $N$ methylpyrrolidone solution of the precursor polyamic acid followed by the thermal imidization. The polyamic acid was prepared by condensation of BPDA with ODA in a $N$ methyl-pyrrolidone solution at room temperature. The polymerization solution was filtered, cast onto glass plates at room temperature, and then dried at $60^{\circ} \mathrm{C}$ for $12 \mathrm{~h}$ in a dust-free chamber. The polyamic acid films were removed from the glass plates and imidized at $230^{\circ} \mathrm{C}$ for $10 \mathrm{~h}$ in a vacuum. The polyimide films thus obtained (BO-A1) were then annealed at $290^{\circ} \mathrm{C}$ for $3 \mathrm{~h}$ under $\mathrm{N}_{2}$ atmosphere to obtain BO-A2 sample films. The films 10 $25 \mu \mathrm{m}$ thick were usually used, while the films
$50-80 \mu \mathrm{m}$ thick were used for measurement of the diffusion coefficients for $\mathrm{H}_{2}$.

Differential scanning calorimetry (DSC) data were measured with a Rigakudenki Thermal Analyzer at a heating rate of $20^{\circ} \mathrm{C}$. The glass transition temperature $\left(T_{\mathrm{g}}\right)$ was measured by the penetration method with a Rigakudenki Thermomechanical analyzer (TMA). Wide angle X-ray diffraction (WAXD) were measured with a Rigakudenki X-ray diffractometer using $\mathrm{Cu}-K_{\alpha}$ radiation wavelength. The density was measured by the floating method using potassium iodide-water solutions with an accuracy of $\pm 0.001 \mathrm{~g} \mathrm{~cm}^{-3}$.

The vacuum time-lag method similar to that described by Toi ${ }^{11}$ was used to measure permeability and diffusion coefficients. Permeate receivers of 30,100 , and $400 \mathrm{~cm}^{3}$ in volume were used depending on the permeation rate. The pressure in the receiver was monitored with a MKS Baratron model 220BA pressure transducer having the measurement range from $10^{-3}$ to 10 Torr. The permeation cell was composed of a feed side, permeate side, and outside rooms. ${ }^{11}$ Before each experimental run, the feed and permeate side rooms were evacuated upto 0.05 Torr and $10^{-5}$ Torr, respectively, for a period more than 10 times the diffusion time-lag in the previous experimental run. The outside room was also evacuated

Table I. Characterization of BPDA-ODA polyimide films

\begin{tabular}{|c|c|c|c|}
\hline \multirow{2}{*}{ Samples } & \multirow{2}{*}{ Preparation conditions } & \multirow{2}{*}{$\frac{\text { Density }}{\mathrm{g} \mathrm{cm}^{-3}}$} & \multirow{2}{*}{$\frac{V_{\mathrm{f}}^{\mathrm{a}}}{-}$} \\
\hline & & & \\
\hline BO-1 & As cast (dried at $170^{\circ} \mathrm{C}, 20 \mathrm{~h}$ in vacuum) & 1.366 & 0.121 \\
\hline BO-2 & Annealed at $270^{\circ} \mathrm{C}, 3 \mathrm{~h}$, in vacuum & 1.403 & 0.097 \\
\hline BO-3 & Annealed at $300^{\circ} \mathrm{C}, 2 \mathrm{~h}$ in $\mathrm{N}_{2}$ flow & 1.409 & 0.093 \\
\hline BO- $4^{\mathrm{c}}$ & Annealed at $285^{\circ} \mathrm{C}, 6 \mathrm{~h}$ in vacuum & 1.399 & 0.100 \\
\hline $\mathrm{BO}-5^{\mathrm{c}}$ & Annealed at $304^{\circ} \mathrm{C}, 6 \mathrm{~h}$ in vacuum & 1.402 & 0.098 \\
\hline Upilex-R & Commercially available ${ }^{b}$ & 1.398 & 0.100 \\
\hline BO-A1 & Imidized at $230^{\circ} \mathrm{C}, 10 \mathrm{~h}$ in vacuum & 1.375 & 0.115 \\
\hline BO-A2 & Annealed at $290^{\circ} \mathrm{C}, 3 \mathrm{~h}$ in $\mathrm{N}_{2}$ flow & 1.403 & 0.097 \\
\hline
\end{tabular}

a $V_{\mathrm{f}}$ is the free volume fraction calculated by the method of Bondi.

b Ube Industries Ltd.

c About $80 \mu \mathrm{m}$ thick. 
upto 0.05 Torr in order to make the blank leak level significantly low. The permeation experiments for $\mathrm{H}_{2}, \mathrm{CO}, \mathrm{CO}_{2}$, and $\mathrm{CH}_{4}$ were carried out at an upstream pressure of $10 \mathrm{~atm}$ and in the temperature range from $25^{\circ} \mathrm{C}$ to $110^{\circ} \mathrm{C}$ at a blank leak rate of less than 1/10 times the permeation rate. All data presented in this study are the average values for 2 or 3 runs. The apparent diffusion coefficient $D$ was calculated from eq 1 .

$$
D=l^{2} /(6 \theta)
$$

where $l$ is film thickness and $\theta$ is diffusion timelag. The apparent solubility coefficient $S$ was calculated from the equation, $S=P / D$.

\section{RESULTS AND DISCUSSION}

The details of characterization of $\mathrm{BO}-1,-2$, -3 and Upilex- $\mathrm{R}$ were reported in the previous paper. ${ }^{9}$ From the data of DSC, TMA, WAXD and density, it was found that BO-1 was amorphous and that BO-2, BO-3 and Upilex-R, which were annealed above $T_{\mathrm{g}}$ $\left(270^{\circ} \mathrm{C}\right)$, had some degree of ordering due to the molecular aggregation of polymer chain segments. This drastic morphological change with the annealing above $T_{\mathrm{g}}$ was characteristically observed for the BPDA-ODA polyimide but not for BPDA-based polyimides containing sulfonyl or methylene linkage instead of the ether linkage.9,12 Figure 1 shows DSC curves of $\mathrm{BO}-\mathrm{Al}$ prepared by imidizing the polyamic acid films at a temperature far below $T_{\mathrm{g}}$ of the polyimide. An exothermic peak appeared at about $280^{\circ} \mathrm{C}$ only in the first run, being quite similar to the case of $\mathrm{BO}-1$. The density of BO-A1 was only a little higher than that of BO-1. The WAXD curve of BO-A1 was broad and structureless, as shown in Figure 2. On the other hand, the WAXD curve of $\mathrm{BO}$ A2 prepared by annealing BO-A1 above $T_{\mathrm{g}}$ had sharp reflections superimposed on a broad diffuse one, as shown in Figure 2, and was similar to that of BO-3. The density of BO-A2 was much higher than that of $\mathrm{BO}-\mathrm{Al}$ and the

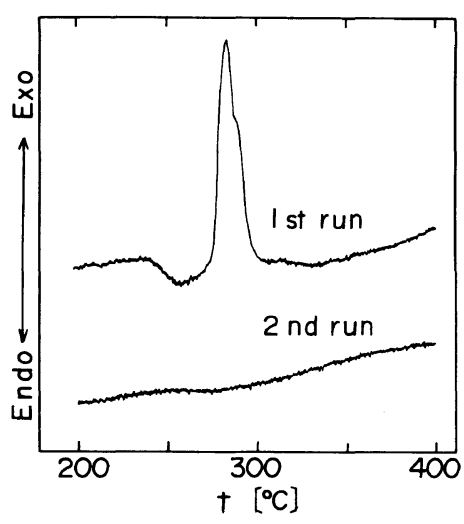

Figure 1. DSC curves of BO-A1.

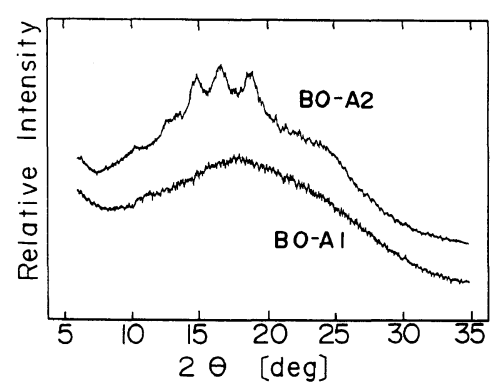

Figure 2. WAXD curves of BO-A1 and BO-A2.

same as that of $\mathrm{BO}-2$. These results indicate that $\mathrm{BO}-\mathrm{A} 1$ was amorphous and that $\mathrm{BO}-\mathrm{A} 2$ was in a molecularly-aggregated state similar to that for $\mathrm{BO}-2$ and $\mathrm{BO}-3$.

Two kinds of models have been proposed for the morphology of PMDA-ODA polyimide, namely, a heterogeneous two-phase structure $^{13}$ and a more-diffuse model. ${ }^{14}$ The morphology of BPDA-ODA polyimide has not been elucidated in detail, yet. Therefore, the specific volume (reciprocal of the density, $1 / d$ ) was used as a measure of the average degree of molecular aggregation in the present study. The average degree of the aggregation was in the following order $\mathrm{BO}-3>\mathrm{BO}-2$ $\mathrm{BO}-5-\mathrm{BO}-\mathrm{A} 2>\mathrm{BO}-4-\mathrm{Upilex}-\mathrm{R} \gg \mathrm{BO}-$ $\mathrm{A} 1>\mathrm{BO}-1$. The average free-volume fraction $\left(V_{\mathrm{f}}\right)$ was calculated by the method of Bondi, ${ }^{15}$ using the density data shown in Table I.

The solubility and diffusion coefficients of 


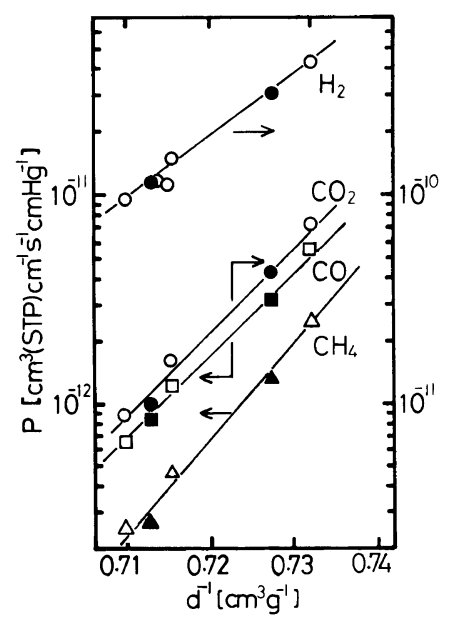

Figure 3. Relation of the permeability coefficients for $\mathrm{H}_{2}, \mathrm{CO}, \mathrm{CO}_{2}$, and $\mathrm{CH}_{4}$ in BPDA-ODA polyimide films at $50^{\circ} \mathrm{C}$ to the specific volume. The open keys are for $\mathrm{BO}-1$ to BO-5. The closed keys are for BO-A1 and BOA2.

gases with high condesability in the glassy polymers are well-known to be dependent on pressure and have been described by the dualmode sorption and transport model. ${ }^{10}$ The analysis of the gas sorption and transport properties of the glassy polymers in terms of the dual-mode model requires sorption and permeation experiments over the wide range of pressure. The purpose of this study was to investigate the influence of the film-casting methods and the morphology of the films on the gas permeability and permselectivity. Therefore, in the present study, the permeability coefficient and diffusion time-lag were measured only at an up-stream pressure of $10 \mathrm{~atm}$, where pressure dependence of $\mathrm{P}$ for $\mathrm{CO}_{2}$ became lower.

Figures 3, 4, and 5 show the relation of the permeability, diffusion, and solubility coefficients, respectively, for $\mathrm{H}_{2}, \mathrm{CO}, \mathrm{CO}_{2}$, and $\mathrm{CH}_{4}$ to the specific volumes of the films. The $P, D$, and $S$ for each gas decreased with decrease in the specific volume. The relative decreases in $P$ and $D$ depended on the molecular size of the gas, while those in $\mathrm{S}$ hardly did so. The value of $S$ for each gas in BO-3 was

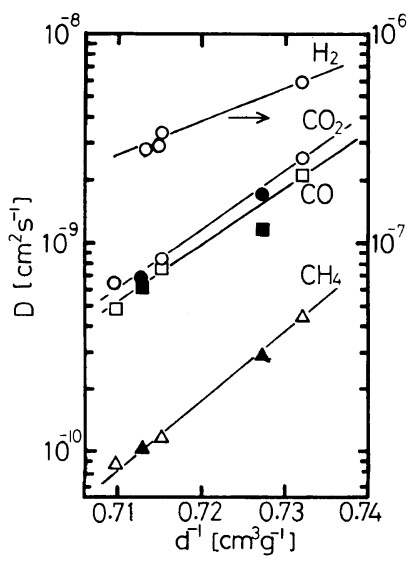

Figure 4. Relation of the diffusion coefficients for $\mathrm{H}_{2}$, $\mathrm{CO}, \mathrm{CO}_{2}$, and $\mathrm{CH}_{4}$ in BPDA-ODA polyimide films at $50^{\circ} \mathrm{C}$ to the specific volume. The open keys are for $\mathrm{BO}-1$ to BO-5. The closed keys are for BO-A1 and BO-A2.

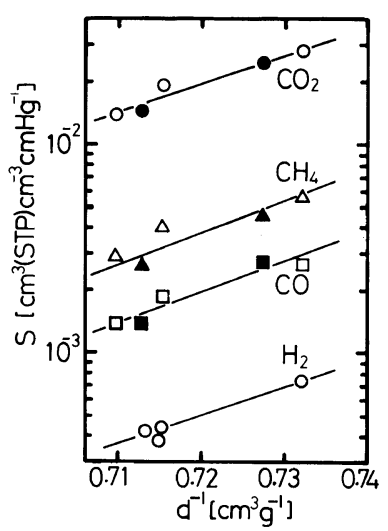

Figure 5. Relation of the solubility coefficients for $\mathrm{H}_{2}$, $\mathrm{CO}, \mathrm{CO}_{2}$, and $\mathrm{CH}_{4}$ in BPDA-ODA polyimide films at $50^{\circ} \mathrm{C}$ to the specific volume. The open keys are for BO-1 to BO-5. The closed keys are for BO-A1 and BO-A2.

about $50 \%$ of the corresponding one in BO- 1 . The degree of decrease in $\mathrm{S}$ was similar to that in $D$ for $\mathrm{H}_{2}$ and fairly smaller than that in $D$ for the other gases investigated.

Figure 6 shows plots of the permeability ratios $P_{\mathrm{H}_{2}} / P_{\mathrm{CO}}$ and $P_{\mathrm{H}_{2}} / P_{\mathrm{CH}_{4}}$, versus the permeability coefficients, $P_{\mathrm{H}_{2}}$. The gas separation properties were summarized in Table II. The permselectivity increased with decrease in $P_{\mathrm{H}_{2}}$. On going from BO-1 to BO-3, $P_{\mathrm{H}_{2}}$ decreased by a factor of $1 / 5$, while the permselectivity 
Table II. Permeability, diffusion and solubility coefficients for $\mathrm{H}_{2}$, and the ratios of each coefficient for $\mathrm{H}_{2} / \mathrm{CO}$ and $\mathrm{H}_{2} / \mathrm{CH}_{4}$ in BPDA-ODA polyimide films at $50^{\circ} \mathrm{C}^{\text {a }}$

\begin{tabular}{lccccccccc}
\hline \multicolumn{1}{c}{ Samples } & $P_{\mathrm{H}_{2}}$ & $D_{\mathrm{H}_{2}}$ & $S_{\mathrm{H}_{2}}$ & $P_{\mathrm{H}_{2}} / P_{\mathrm{CO}}$ & $D_{\mathrm{H}_{2}} / D_{\mathrm{CO}}$ & $S_{\mathrm{H}_{2}} / S_{\mathrm{CO}}$ & $P_{\mathrm{H}_{2}} / P_{\mathrm{CH}_{4}}$ & $D_{\mathrm{H}_{2}} / D_{\mathrm{CH}_{4}}$ & $S_{\mathrm{H}_{2}} / S_{\mathrm{CH}_{4}}$ \\
\hline BO-1 & 43.7 & 5.9 & 7.4 & 79 & 280 & 0.28 & 176 & 1300 & 0.13 \\
BO-A1 & 30.4 & - & - & 96 & - & - & 232 & - & - \\
Upilex-R & 14.8 & 3.4 & 4.4 & 121 & 510 & 0.24 & 320 & 2900 & 0.11 \\
BO-A2 & 11.3 & - & - & 135 & - & - & 420 & - & - \\
BO-3 & 9.4 & - & - & 142 & - & - & 380 & - & - \\
\hline
\end{tabular}

a $P$ is in $10^{-11} \mathrm{~cm}^{3}(\mathrm{STP}) \mathrm{cm}^{-1} \mathrm{~s}^{-1} \mathrm{cmHg}^{-1}, D$ is in $10^{-7} \mathrm{~cm}^{2} \mathrm{~s}^{-1}$, and $S$ is in $10^{-4} \mathrm{~cm}^{3}(\mathrm{STP}) \mathrm{cm}^{-3} \mathrm{cmHg}^{-1}$.

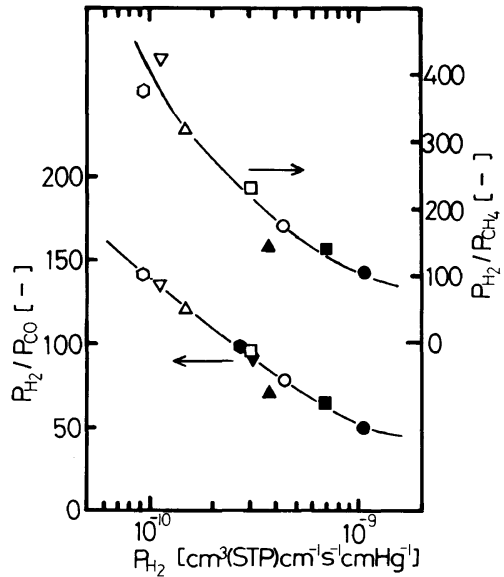

Figure 6. Plots of the ideal separation factors for the $\mathrm{H}_{2} / \mathrm{CO}$ and $\mathrm{H}_{2} / \mathrm{CH}_{4}$ systems versus the permeability coefficients for $\mathrm{H}_{2}$ in PBDA-ODA polyimide films at 50 and $100^{\circ} \mathrm{C}$. $\bigcirc$ and $\bigcirc, \mathrm{BO}-1 ; \square$ and $\square$, BO-A $1 ; \triangle$ and $\boldsymbol{\Delta}$, Upilex-R; $\nabla$ and $\boldsymbol{\nabla}$, BO-A2; 0 and $\boldsymbol{\Delta}$, BO-3. The open and closed keys are at 50 and $100^{\circ} \mathrm{C}$, respectively.

increased by a factor of 1.8 and 2.2 for $\mathrm{H}_{2} / \mathrm{CO}$ and $\mathrm{H}_{2} / \mathrm{CH}_{4}$, respectively. The diffusivity ratios in Upilex-R were 1.8 and 2.2 times larger for the $\mathrm{H}_{2} / \mathrm{CO}$ and $\mathrm{H}_{2} / \mathrm{CH}_{4}$ systems, respectively, than those in $\mathrm{BO}-1$, while their solubility ratios were almost the same. Enhancement of permselectivity for these systems was found due to enhancement of the diffusivity selectivity with decrease in specific volume. Although Hoehn has reported for $F$ containing polyimides that appropriate annealing-treatment significantly enhanced the permselectivity for the $\mathrm{H}_{2} / \mathrm{CH}_{4}$ system with an appreciable increase in $P_{\mathrm{H}_{2}},{ }^{3)}$ for the BPDAODA polyimide investigated in this study, the

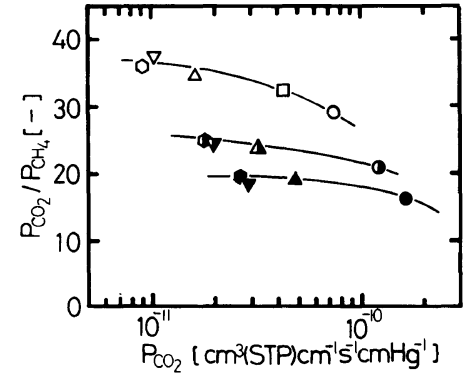

Figure 7. Plots of the ideal separation factors for the $\mathrm{CO}_{2} / \mathrm{CH}_{4}$ system versus the permeability coefficients for $\mathrm{CO}_{2}$ in BPDA-ODA polyimide films at 50, 80, and $100^{\circ} \mathrm{C}$. $\bigcirc$, , and $\bigcirc$, BO- $1 ; \square, \mathrm{BO}-\mathrm{A} 1 ; \triangle, \nabla$, and $\boldsymbol{\Delta}$, Upilex-R; $\nabla, \Delta$, and $\boldsymbol{\nabla}, \mathrm{BO}-\mathrm{A} 2 ; 0$, $\boldsymbol{\nabla}$, and $\boldsymbol{\bullet}$, BO-3. The open, semi-open, and closed keys are at 50,80, and $100^{\circ} \mathrm{C}$, respectively.

enhancement in the permselectivity was followed by significant reduction in $P_{\mathrm{H}_{2}}$.

Figure 7 shows the relation of the permeability ratio, $P_{\mathrm{CO}_{2}} / P_{\mathrm{CH}_{4}}$, to the permeability coefficient, $P_{\mathrm{CO}_{2}}$. The gas separation properties are summarized in Table III. The permselectivity increased only slightly with a significant decrease in $P_{\mathrm{CO}_{2}}$. This is different from the result mentioned above for the $\mathrm{H}_{2} / \mathrm{CO}$ and $\mathrm{H}_{2} / \mathrm{CH}_{4}$ systems. With decrease in specific volume caused by annealing, the diffusivity ratio increased only slightly and the solubility ratio hardly changed, resulting in only slight enhancement of permselectivity. Therefore, BO-1, the as-cast film and amorphous, is more suitable for the $\mathrm{CO}_{2} / \mathrm{CH}_{4}$ gas separation than the others which are in the molecularly aggregated state. A similar result has been reported for PMDA-ODA polyimide. ${ }^{7}$ 
Table III. Permeability, diffusion and solubility coefficients and the ratios of each coefficient for $\mathrm{CO}_{2} / \mathrm{CH}_{4}$ in BPDA-ODA polyimide films at $50^{\circ} \mathrm{C}^{\mathrm{a}}$

\begin{tabular}{lcccccc}
\hline Samples & $P_{\mathrm{CO}_{2}}$ & $D_{\mathrm{CO}_{2}}$ & $S_{\mathrm{CO}_{2}}$ & $P_{\mathrm{CO}_{2} / P_{\mathrm{CH}_{4}}}$ & $D_{\mathrm{CO}_{2} / D_{\mathrm{CH}_{4}}}$ & $S_{\mathrm{CO}_{2}} / S_{\mathrm{CH}_{4}}$ \\
\hline BO-1 & 7.15 & 2.53 & 2.8 & 28.7 & 5.7 & 5.0 \\
BO-A1 & 4.29 & 1.72 & 2.5 & 32.7 & 5.9 & 5.5 \\
Upilex-R & 1.61 & 0.84 & 1.9 & 34.6 & 7.3 & 5.6 \\
BO-A2 & 1.01 & 0.70 & 1.5 & 37.5 & 6.7 & 5.6 \\
BO-3 & 0.90 & 0.64 & 1.4 & 35.8 & 7.4 & 4.7 \\
\hline
\end{tabular}

a $P$ is in $10^{-11} \mathrm{~cm}^{3}(\mathrm{STP}) \mathrm{cm}^{-1} \mathrm{~s}^{-1} \mathrm{cmHg}^{-1}, D$ is in $10^{-9} \mathrm{~cm}^{2} \mathrm{~s}^{-1}$, and $S$ is in $10^{-2} \mathrm{~cm}^{3}(\mathrm{STP}) \mathrm{cm}^{-3} \mathrm{cmHg}^{-1}$.

Table IV. Activation energies of the permeability and diffusion coefficients and sorption enthalpies for $\mathrm{H}_{2}, \mathrm{CO}_{2}$, and $\mathrm{CH}_{4}$ in BPDA-ODA polyimide films ${ }^{\mathrm{a}}$

\begin{tabular}{|c|c|c|c|c|c|c|c|c|c|}
\hline \multirow{2}{*}{ Sample } & \multicolumn{3}{|c|}{$\mathrm{H}_{2}$} & \multicolumn{3}{|c|}{$\mathrm{CO}_{2}$} & \multicolumn{3}{|c|}{$\mathrm{CH}_{4}$} \\
\hline & $\Delta E_{\mathrm{P}}$ & $\Delta E_{\mathrm{D}}$ & $\Delta H$ & $\Delta E_{\mathrm{P}}$ & $\Delta E_{\mathrm{D}}$ & $\Delta H$ & $\Delta E_{\mathrm{P}}$ & $\Delta E_{\mathrm{D}}$ & $\Delta H$ \\
\hline BO-1 & 18.0 & 25.4 & -7.4 & 16.1 & 34.3 & -18 & 27.7 & 42.5 & -15 \\
\hline Upilex-R & 18.5 & 26.7 & -8.3 & 20.5 & 39.3 & -19 & 34.2 & 48.8 & -15 \\
\hline BO-A2 & - & - & - & 21.3 & 38.3 & -17 & 35.1 & 50.9 & -16 \\
\hline BO-3 & - & - & - & 22.2 & 39.5 & -17 & 34.3 & 52.9 & -19 \\
\hline BO-4 & 21.1 & 26.8 & -6.2 & - & - & - & - & - & - \\
\hline BO-5 & 20.6 & 26.1 & -6.1 & - & - & - & - & - & - \\
\hline
\end{tabular}

a $\Delta E_{\mathrm{P}}, \Delta E_{\mathrm{D}}$, and $\Delta H$ are in $\mathrm{kJ} \mathrm{mol}^{-1}$.

Activation energies of the permeability and diffusion coefficients, $\Delta E_{\mathrm{P}}$ and $\Delta E_{\mathrm{D}}$, and sorption enthalpies $\Delta H$ are listed in Table IV. The $\Delta E_{\mathrm{p}}$ for every gas increased with decrease in specific volume. This was attributed to an increase in $\Delta E_{\mathrm{D}}$ with decrease in specific volume and $\Delta H$ remained constant within the experimental errors. Both the magnitude of $\Delta E_{\mathrm{D}}$ and the relative increase in $\Delta E_{\mathrm{D}}$ were greater for the larger penetrant molecule; that is, they were in the order of $\mathrm{CH}_{4}>$ $\mathrm{CO}_{2} \gg \mathrm{H}_{2}$. The activation energy for diffusion is regarded as the energy necessary for the formation of the so-called "holes" of which the minimum size required depends on the penetrant molecule. ${ }^{16}$ The diffusion of the larger penetrant molecule needs greater activation-energy as a result of the need of larger "holes". The experimental results indicated that the energy necessary for the formation of the larger "holes" increases significantly with decrease in the specific volume, in the case of BPDA-ODA polyimide.

Both BO-A1 and BO-A2 may be assumed structurally more heterogeneous and richer in the so-called microvoids than $\mathrm{BO}-1$ to $\mathrm{BO}-5$, because the former type of sample films were prepared by the thermal imidization of the films of the precursor polyamic acid; that is, it might become more difficult with progress of the imidization for the segment chain to take more stable and more preferential structures. because of decrease in the mobility of the segment chains. If this is the case, some differences in the permeation properties between the former and latter types of the sample films should be observed. In Figures $3-5$ where the permeability, diffusion, and solubility coefficients are plotted against the specific volume, the data points for each gas in these two types of the sample films are on a line, indicating that there is no appreciable difference in the permeation properties attributed to the different film-casting methods. Therefore, it is 
considered that there is no appreciable difference in the morphology between these two types of sample films, except for differences in the specific volume attributed to differences in the thermal treatment conditions.

The following two different types of explanations are possible for the effect of morphology on the solubility and diffusion coefficients. One explanation is based on the onephase model. In this case, we assume that BPDA-ODA polyimide is composed of one diffuse phase rather than two distinct phases, as proposed for PMDA-ODA polyimide as the more-diffuse model. ${ }^{14}$ Then, the $V_{\mathrm{f}}$ values shown in Table I can be used for interpreting the variation in $\mathrm{D}$ with the morphology as follows. According to the free-volume theory of Fujita, ${ }^{17}$ the thermodynamic diffusion coefficient $D_{\mathrm{T}}$ for a gas molecule in polymer matrix is given by eq 2 .

$$
D_{\mathrm{T}}=R T A_{\mathrm{d}} \exp \left(-B_{\mathrm{d}} / V_{\mathrm{f}}\right)
$$

where $R$ is the gas constant, $T$ is the absolute temperature, $V_{\mathrm{f}}$ is the free volume fraction of the system, and $A_{\mathrm{d}}$ and $B_{\mathrm{d}}$ are parameters which depend on the molecular size and shape of the gas. Although the diffusion coefficients $D$ determined in the present study are the apparent ones and dependent on pressure, especially for $\mathrm{CO}_{2}$ and $\mathrm{CH}_{4}$, the correlation of $D$ for each gas with $V_{\mathrm{f}}$ of the sample films was sought, as shown in Figure 8. The linear relation between $\ln D$ and $V_{\mathrm{f}}^{-1}$ was obtained for every gas investigated. The values of $A_{\mathrm{d}}$ and $B_{\mathrm{d}}$ were determined from straight lines obtained by eq 2 , and are listed in Table $\mathrm{V}$ together with the molecular diameters of gases. ${ }^{18}$ Parameter $B_{\mathrm{d}}$ is related to the critical volume necessary for diffusion of a gas molecule and therefore should be larger for a gas with larger molecular diameter. This tendency is valid for the present case, as can be seen from Table $\mathrm{V}$ and Figure 8 . Thus, significant decreases in $D$ can be interpreted as due to those in $V_{\mathrm{f}}$ with morphology change induced by annealing above $T_{\mathrm{g}}$.

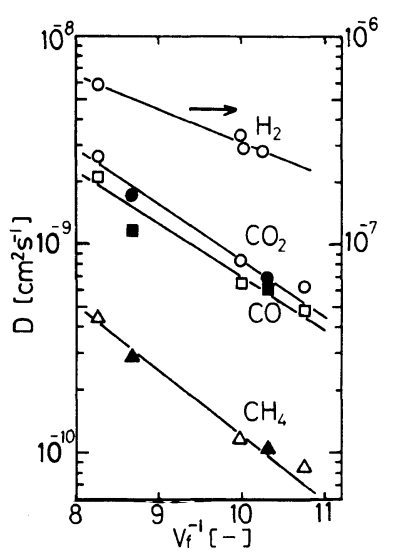

Figure 8. Correlation of the diffusion coefficients for $\mathrm{H}_{2}, \mathrm{CO}, \mathrm{CO}_{2}$, and $\mathrm{CH}_{4}$ in BPDA-ODA polyimide films at $50^{\circ} \mathrm{C}$ with the free volume fraction of the films. The open keys are for BO-1 to BO-5. The closed keys are for $\mathrm{BO}-\mathrm{A} 1$ and $\mathrm{BO}-\mathrm{A} 2$.

Table V. Values of parameters $A_{\mathrm{d}}$ and $B_{\mathrm{d}}$ for $\mathrm{H}_{2}$, $\mathrm{CO}_{2}, \mathrm{CO}$, and $\mathrm{CH}_{4}$ in BPDA-ODA polyimide films and molecular diameters of gases

\begin{tabular}{|c|c|c|c|}
\hline \multirow{2}{*}{ Gas } & Diameter & $A_{\mathrm{d}} \times 10^{10}$ & $B_{\mathrm{d}}$ \\
\hline & $\mathrm{nm}$ & $\mathrm{mol}^{-1}$ & - \\
\hline $\mathrm{H}_{2}$ & 0.27 & 49 & 0.37 \\
\hline $\mathrm{CO}$ & 0.37 & 0.95 & 0.59 \\
\hline $\mathrm{CO}_{2}$ & 0.39 & 1.6 & 0.63 \\
\hline $\mathrm{CH}_{4}$ & 0.41 & 0.57 & 0.72 \\
\hline
\end{tabular}

It has been reported that the solubility coefficients for gases in rubbery polymers hardly change when the specific volume is reduced by chemical or radiation-induced crosslinking, keeping the degree of the crystallinity constant. ${ }^{19,20}$ It has also been reported that the densification of polycarbonate films caused by the sub- $T_{\mathrm{g}}$ annealing results in a decrease in $S$ for $\mathrm{CO}_{2}$, primarily due to decrease in the Langmuir capacity constant, but no appreciable decrease in the Henry's law solubility constant. ${ }^{21}$ Therefore, it is difficult to explain the decrease in $\mathrm{S}$ according to the onephase model. However, we have recently found the trend that the Henry's law solubility constant for $\mathrm{CO}_{2}$ is larger for an amorphous glassy polymer with a higher value of $V_{\mathrm{f}} \cdot{ }^{12}$ The 
present result might be regarded as an example of this trend. Further study is necessary.

Another explanation is based on the two phase model, where sorption and transport of penetrants are considered to occur only in the amorphous phase. ${ }^{2-24}$ In this case, we assume that BPDA-ODA polyimide has a heterogeneous two phase structure composed of ordered and amorphous phases, as proposed for PMDA-ODA polyimide. ${ }^{13}$ The decreases in $\mathrm{S}$ and $\mathrm{D}$ due to the presence of the ordered phase are expressed by eq 3 and 4 .

$$
\begin{gathered}
S=S_{\mathrm{a}} \phi_{\mathrm{a}} \\
D=D_{\mathrm{a}} /(\tau \cdot \beta)
\end{gathered}
$$

where $S_{\mathrm{a}}$ and $D_{\mathrm{a}}$ are the solubility and diffusion coefficients for the penetrant in a completely amorphous polymer, $\phi_{\mathrm{a}}$ is the amorphous volume fraction, $\tau$ is a tortuosity factor, and $\beta$ is a chain immobilization factor reflecting decreased chain segmental mobility in the amorphous phase due to the proximity of the ordered phase. Equation 3 is considered to be a good approximation of gases with low condensability such as $\mathrm{He}$ and $\mathrm{H}_{2}$, because of the negligible dominance of Langmuir-mode sorption. ${ }^{24}$ Both the density of ordered phase and $\phi_{\mathrm{a}}$ of each film were evaluated from the sorption data for $\mathrm{H}_{2}$ according to eq 3 , as shown in Table VI. The estimated density of the ordered phase $\left(1.46 \mathrm{~g} \mathrm{~cm}^{-3}\right)$ was $6.9 \%$ larger than that for the amorphous phase $\left(1.366 \mathrm{~g} \mathrm{~cm}^{-3}\right.$ for BO-1), but the difference between them was about $1 / 2$ times as large as average one for typical semicrystalline polymers, ${ }^{25)}$ suggesting fairly loose packing of the ordered phase for BPDA-ODA polyimide. Assuming the relation of $\tau=1 / \phi_{\mathrm{a}}{ }^{23.25}$ the $\beta$ values were evaluated from eq 4 , and are listed in Table VI. The $\beta$ values for $\mathrm{CO}, \mathrm{CO}_{2}$, and $\mathrm{CH}_{4}$ were much greater than unity except for BO-Al and suggest the significant effect of the ordered phase on the chain segmental mobility in the amorphous phase. This is similar to the result for $\mathrm{CO}_{2}$ in PMDA-ODA polyimide, ${ }^{8}$
Table VI. Amorphous phase fraction and chain immobilization factors for BPDA-ODA polyimide tentatively determined according to the two phases model

\begin{tabular}{llllll}
\hline & & \multicolumn{5}{c}{$\beta$} \\
\cline { 3 - 6 } Samples & $\phi_{\mathrm{a}}$ & $\mathrm{H}_{2}$ & $\mathrm{CO}_{2}$ & $\mathrm{CO}$ & $\mathrm{CH}_{4}$ \\
\hline BO-1 & 1.0 & 1.0 & 1.0 & 1.0 & 1.0 \\
BO-A1 & 0.91 & - & 1.4 & 1.6 & 1.4 \\
Upilex-R & 0.67 & 1.0 & 1.8 & 1.8 & 2.2 \\
BO-A2 & 0.62 & - & 2.0 & 1.8 & 2.2 \\
BO-3 & 0.55 & - & 1.8 & 1.9 & 2.2 \\
BO-4 & 0.66 & 1.1 & - & - & - \\
BO-5 & 0.63 & 1.1 & - & - & - \\
\hline
\end{tabular}

but in marked contrast to those reported for PET $(\beta \simeq 1){ }^{24.26}$ Thus, according to the two phase model, the decreases in $D$ and $S$ are interpreted as a result of the decrease in $\phi_{\mathrm{a}}$ and the chain immobilization effect. The large chain immobilization effect for BPDA-ODA and PMDA-ODA polyimides may result from the small size of the amorphous and ordered phases. ${ }^{13}$

At the present, we cannot decide which of these two explanations is more applicable. Further study of the morphology is necessary.

\section{REFERENCES}

1. K. C. O'Brien, W. J. Koros, and G. P. Husk, J. Membrane Sci., 35, 217 (1987).

2. G. F. Sykes and A. K. St. Clair, J. Appl. Polym. Sci., 32, 3725 (1986).

3. H. H. Hoehn, ACS Symp. Ser., 269, 81 (1985).

4. D. G. Pye, J. Appl. Polym. Sci., 20, 287 (1976).

5. A. Nakamura, Kobunshi, 35, 1078 (1986); A. Nakamura, Y. Kusuki, T. Harada, K. Nakagawa, and M. Kinouchi, The 1987 International Congress on Membranes and Membrane Process, Tokyo, 1987 , p 560.

6. K. Haraya, K. Obata, T. Hakuta, and H. Yoshitome, Maku (Membrane), 11, 48 (1986).

7. K. C. O'Brien, W. J. Koros, and G. P. Husk, Polym. Eng. Sci., 27, 211 (1987).

8. K. Okamoto, K. Tanaka, O. Yokoshi, and H. Kita, J. Polym. Sci., Polym. Phys. Ed., in press.

9. K. Okamoto, K. Tanaka, H. Kita, A. Nakamura, and Y. Kusuki, J. Polym. Sci., Polym. Phys. Ed., in press. 
10. D. R. Paul and W. J. Koros, J. Polym. Sci., Polym Phys. Ed., 14, 675 (1976).

11. K. Toi, Hyoumen, 24, 25 (1986).

12. K. Okamoto, K. Tanaka, H. Kita, A. Nakamura, and Y. Kusuki, submitted to J. Polym. Sci., Polym. Phys. Ed.

13. S. Isoda, H. Shimada, M. Kochi, and H. Kambe, $J$. Polym. Sci., Polym. Phys. Ed., 19, 1293 (1981); M. Kochi and H. Kambe, Polym. Eng. Rev., 3, 355 (1983); J. Polym. Sci., Polym. Phys. Ed., 22, 1979 (1984).

14. T. P. Russell, J. Polym. Sci., Polym. Phys. Ed., 22, 1105 (1984).

15. A. Bondi, J. Phys. Chem., 68, 441 (1964); "Physical Properties of Molecular Crystals, Liquids and Gases," John Wiley \& Sons, New York, N. Y., 1968, p 450.

16. V. Stannett, "Diffusion in Polymers," J. Crank and G. S. Park, Ed., Academic Press, New York, N. Y., 1968, p 42.

17. H. Fujita, Fortschr. Hochpolym. Forsch., 3, 1 (1961).
18. A. S. Michaels and H. J. Bixler, J. Polym. Sci., 50, 413 (1961).

19. R. M. Barrer and G. Skirrow, J. Polym. Sci., 3, 549 (1948); ibid., 3, 564 (1948); R. M. Barrer, J. A. Barrie, and P. S.-L. Wong, Polymer, 9, 609 (1968).

20. H. Kita, M. Muraoka, K. Tanaka, and K. Okamoto, Polym. J., 20, 485 (1988).

21. A. H. Chan and D. R. Paul, Polym. Eng. Sci., 20, 87 (1980).

22. A. S. Michaels and R. B. Paker Jr., J. Polym. Sci., 41, 53 (1959).

23. A. S. Michaels and H. J. Bixler, J. Polym. Sci., 50, 393 (1961); ibid., 50, 413 (1961).

24. A. S. Michaels, W. R. Vieth, and J. A. Barrie, J. Appl. Phys., 34, 1 (1963); ibid., 34, 14 (1963).

25. D. W. Van Krevelen, "Properties of Polymers," Elsevier Scientific Publishing Company, Amsterdam, 1976, p 60.

26. W. J. Koros and D. R. Paul, J. Polym. Sci., Polym. Phys. Ed., 16, 2171 (1978). 